\title{
Decomposing the Effecting Factors of Urbanization on Energy Consump- tion of China
}

\author{
Xueling Guan and Min Zhou*
}

School of Management, China University of Mining and Technology, Xuzhou, Jiangsu, China

\begin{abstract}
With a rapid growth rate, urbanization is casting a profound impact on both production and residential sector in China, influencing the energy consumption accordingly. Based on theoretical analysis and LMDI (Log Mean Divisia Index) method, the change of energy consumption in the two sectors is decomposed into several effects related to urbanization. According to the empirical result from 1980 to 2012, the change of energy in production sector is the dominating factor of the total energy consumption change in China. Among the effecting factors, the economic growth urged by urbanization is the main factor driving the increase of energy consumption, while technical improvement is the key factor in energy saving. In residential sector, the energy consumption difference between urban and rural residents is also confirmed. Suggestions in reduce energy consumption during urbanization in China are given accordingly.
\end{abstract}

Keywords: Decomposition, effecting factors, energy consumption, urbanization.

\section{INTRODUCTION}

As the most populated country and largest developing country worldwide, China is experiencing a powerful trend of urbanization. By the end of 2013, the demographic urbanization rate reached $53.7 \%$ in China (China Statistic Yearbook 2014). Seeing urbanization as the new engine of future economic growth, the national government has issued a series of policies to promote its development. Urbanization not only involves labour force movement from rural to urban areas, but also accompanies with changing of economic activities and organizational patterns in both production and residential sectors which have great impact on energy consumption. The relationship of urbanization and energy consumption has been widely studied, most of them focused on the correlation and causality of the two variables. Analyzing cross section data from 59 countries, Jones [1] found there is a significant correlation between urbanization and energy consumption. Using data from different areas in different time period, Parikh and Shukla [2], Imai [3] draw similar conclusion. While Kenworthy and Laube [4], Ewing and Rong [5] believe more urbanized areas had lower per capita energy consumption. For the causality study, by study the nexus of energy and GDP, Mishra et al. [6] detected mutual causality between urbanization and energy consumption for Pacific Island countries in short-run. Shahbaz and Lean [7] analyzed the role of industrialization and urbanization in Tunisia, reporting that urbanization is the Granger cause of energy consumption in both long-run and short-run. For the relationship of the two variables in China, based on the neoclassical aggregate production technology, Wei et al. [8] found that the process of urbanization had caused the increase and decrease for energy consumption at the same time. Applying ARDL and FDM model, Liu [9] detected a unidirectional Granger cause running from urbanization to energy consumption in both long-term and short-term. Using STIRPAT model, Lin et al. [10] found urbanization has positive effect on energy consumption during the year 1978 to 2006.

Being the largest energy consumer as well as the number one carbon emission country, the energy and its related emission issue in China has not only drown worldwide attention but also posed challenges for the further development of China and its urbanization. As urbanization is a complicated phenomenon involving profound changes in social and economic aspects, the effects of urbanization to energy consumption is also mixed. On one hand, urbanization drives rising in infrastructure construction, transportation and household consumption which may lead increase in energy consumption. On the other hand, advanced way of production promoted by urbanization brings economics of scale which might decrease the energy consumption. Recently, more studies are focusing on exploring the internal relation of urbanization on influencing energy consumption and its environmental influence. By analyzing the city-related production, mobility and transport, infrastructure, urban density, and private households, Madlener and Sunak [11] found urbanization within the different sectors cause a substantial increase in energy demand and to a change in the fuel mix. Martínez-Zarzoso and Maruotti [12] investigated the impacts of urbanization on $\mathrm{CO}_{2}$ emissions in different developing countries. Found the demographic effect had different impact in three groups during the period of 1975 to 2003. Using a time-series analysis, Wang [13] detected the effects of urbanization on residential energy consumption and production energy consumption; found the effects are different in the two sectors. 


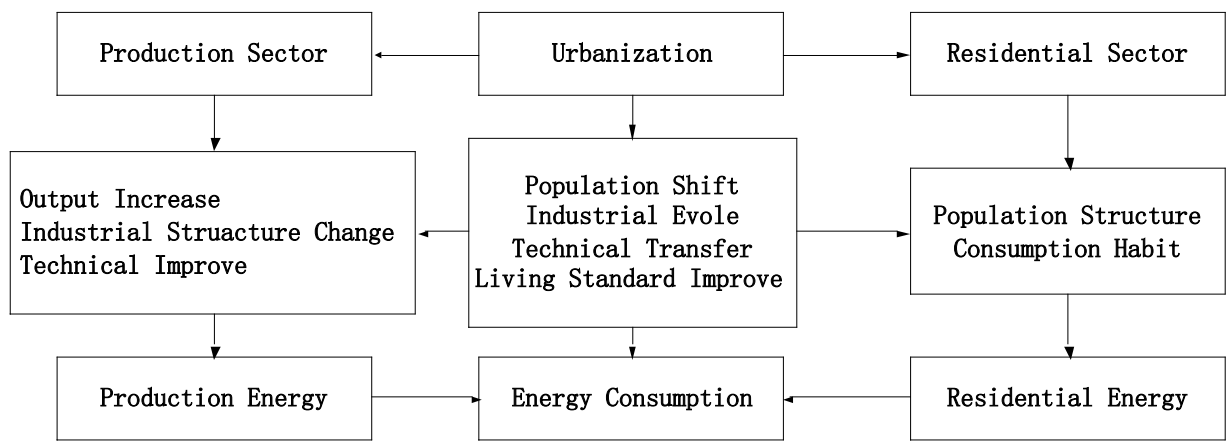

Fig (1). The effecting mechanism of urbanization to energy consumption.

These pioneer studies unfolded the nexus of urbanization and energy consumption, considering urbanization one of the impacting factors of the change in energy consumption. However, there are few studies decomposed the different effects of urbanization and their contributions to energy consumption. Here, the study catalogs the influences of urbanization into production sector and residential sector, trying to explore their impacts to the change of energy consumption. The rest of the paper is arranged as follows: Section 2 constructs the conceptual framework and decomposing model to describe the effects of urbanization to energy consumption theoretically. Section 3 describes the data source used in the analysis. The results of the LMDI method are listed in Section 4 , in which part the effect of each contributor of urbanization in both production and residential sectors to the change of energy consumption is also discussed. In section 5 , the findings and corresponding suggestions are presented.

\section{METHODOLOGY}

\subsection{Conceptual Framework}

Along with the agglomeration of people, capital, industry and technology are clustering to urban area during urbanization, provoking dramatic and profound changes in both production process and residential activities. In production sector, urbanization brought higher economic output by improving productivity. The industrial shifted from primary industry to secondary and tertiary industries as the industrial structure evolving with urbanization. Technical improvement also accrued with advanced technical transferring and spilling over in the process of urbanization. In residential sector, the changing of residential location and improving of living standard result in alterations of living modes and consumption habits.

As shown in Fig. (1), the energy consumption in both production and residential sectors are affected in the process of urbanization. The impacts of urbanization are transmitted by the change of production and living modes to the final energy consumption.

\subsection{LMDI Method}

Decomposition methods are extensively used to quantify the impact of different drivers of energy consumptions and its related $\mathrm{CO} 2$ emissions [14-17]. Based on index theory, index decomposition analysis (IDA) is a well-known decomposition method together with structural decomposition analysis (SDA). Based on input-output tables, the SDA method, a preferred method in studying production effects and final demand effects in energy consumption changes, is challenged to apply in distinguishing urban and rural energy use due to the lack of separate input-output tables [18]. Using aggregated data in a period-wise or time series manner, the IDA method is taking the advantage to analyze how the impacting factors have evolved over time [19]. Due to its readily available data and flexibility of application to disaggregation at different levels, IDA has gained favourable appraise in recent years [20].

Among the several mathematical methods of IDA, logarithmic mean Divisia index (LMDI) method is a preferred method, as its theoretical foundation, adaptability, ease of use and interpretation of results [21]. The LMDI approach has been widely used in the subjects of energy economics and its related carbon emissions [22]. According to the internal mechanism and effects of urbanization to energy consumption illustrated as Table 1, the total energy consumption can be decomposed as Equation 1:

$$
\begin{gathered}
E=P E+R E=\sum \begin{array}{c}
P \times \frac{Y}{P} \times \frac{Y_{i}}{Y} \times \frac{P E_{i}}{Y_{i}} \\
+\sum P \times \frac{P_{j}}{P} \times \frac{R E_{j}}{P_{j}} \\
=\sum P \times E G \times I S_{i} \times T I_{i}+\sum P \times P S_{j} \times C H_{j}
\end{array}
\end{gathered}
$$

where $\mathrm{E}, \mathrm{PE}$ and RE represents total energy consumption, energy consumption in production and residential sector, separately. In production sector, $\mathrm{P}, \mathrm{Y}, \mathrm{Y}_{\mathrm{i}}$ and $\mathrm{PE}_{\mathrm{i}}$ donates population, GDP, GDP of industry i and energy consumption of industry $i$, separately. In residential sector, $P, P_{j}$ and $R E_{j}$ is population, population in $\mathrm{j}$ area and energy consumption in $\mathrm{j}$ area, respectively. The subscript i represents primary, secondary and tertiary industry; $j$ represents urban and rural area. Equals (Y/P), EG is per capita GDP, reflecting the economic growth. Equals $\left(Y_{i} / Y\right), I S_{i}$ is the share of industry $i$ in GDP, reflecting the industrial structure. Equals $\left(\mathrm{PE}_{\mathrm{i}} / \mathrm{Y}_{\mathrm{i}}\right), \mathrm{TI}_{\mathrm{i}}$ is the energy intensity of industry $i$, reflecting the technical improvement. Equals $\left(\mathrm{P}_{\mathrm{j}} / \mathrm{P}\right), \mathrm{PS}_{\mathrm{j}}$ is the share of area $\mathrm{j}$ in total population, reflecting the population structure. Equals $\left(\mathrm{RE}_{\mathrm{j}} /\right.$ $\left.P_{j}\right), R E_{j}$ is the per capita household energy consumption in area $\mathrm{j}$, reflecting the energy consumption habit. According to the LMDI method, differentiating Equation 1 with respect to time, the change of energy consumption can be expressed as Equation 2: 
$\Delta E_{\text {tot }}=E_{\text {tot }}^{t}-E_{\text {tot }}^{0}=\Delta P E+\Delta R E$

$=\left(\Delta E_{p 1}+\Delta E_{e g}+\Delta E_{i s}+\Delta E_{t i}\right)$

$+\left(\Delta E_{p 2}+\Delta E_{p s}+\Delta E_{c h}\right)$

$=\Delta E_{p}+\Delta E_{e g}+\Delta E_{i s}+\Delta E_{t i}+\Delta E_{p s}+\Delta E_{c h}$

where $\Delta E_{t o t}$ donates the change of energy consumption between a target year $\mathrm{t}\left(E_{t o t}^{t}\right)$ and a base year $0\left(E_{t o t}^{0}\right)$, which is decomposed into the change into production sector $(\triangle P E)$ and residential sector $(\triangle R E)$. For production sector, $\triangle P E$ is decomposed to population effect $\left(\Delta E_{p 1}\right)$, economic growth effect $\left(\Delta E_{e g}\right)$, industrial structural effect $\left(\Delta E_{i s}\right)$ and technical improvement effect $\left(\Delta E_{t i}\right)$. For residential sector, $\Delta R E_{\text {is }}$ decomposed to population effect ( $\Delta E_{p 2}$ ), population structure effect ( $\Delta E_{p s}$ ) and consumption habit effect $\left(\Delta E_{c h}\right)$. The population effect in two sectors can be combined and expressed as $\Delta E_{p}$. The effects in production sector and residential sector can be computed by Equation 3 and Equation 4, separately.

$\Delta E_{p 1}= \begin{cases}\sum_{i} L\left(P E^{t}, P E^{0}\right) \ln \left(P^{t} / P^{0}\right), & P E^{t} \times P E^{0} \neq 0 \\ 0 & P E^{t} \times P E^{0}=0\end{cases}$

$\Delta E_{e g}= \begin{cases}\sum_{i} L\left(P E^{t}, P E^{0}\right) \ln \left(E G^{t} / E G^{0}\right), & P E^{t} \times P E^{0} \neq 0 \\ 0, & P E^{t} \times P E^{0}=0\end{cases}$

$\Delta E_{i s}= \begin{cases}\sum_{i} L\left(P E^{t}, P E^{0}\right) \ln \left(I S_{i}^{t} / I S_{i}^{0}\right), P E^{t} \times P E^{0} \neq 0 \\ 0, & P E^{t} \times P E^{0}=0\end{cases}$

$\Delta E_{t i}= \begin{cases}\sum_{i} L\left(P E^{t}, P E^{0}\right) \ln \left(T I_{i}^{t} / T I_{i}^{0}\right), & P E^{t} \times P E^{0} \neq 0 \\ 0, & P E^{t} \times P E^{0}=0\end{cases}$
$\Delta E_{p 2}= \begin{cases}\sum_{j} L\left(R E^{t}, R E^{0}\right) \ln \left(P^{t} / P^{0}\right), & R E^{t} \times R E^{0} \neq 0 \\ 0, & R E^{t} \times R E^{0}=0\end{cases}$

$\Delta E_{p s}= \begin{cases}\sum_{j} L\left(R E^{t}, R E^{0}\right) \ln \left(P S_{j}^{t} / P S_{j}^{0}\right), & R E^{t} \times R E^{0} \neq 0 \\ 0, & R E^{t} \times R E^{0}=0\end{cases}$

$\Delta E_{c h}= \begin{cases}\sum_{j} L\left(R E^{t}, R E^{0}\right) \ln \left(C H_{j}^{t} / C H_{j}^{0}\right), & R E^{t} \times R E^{0} \neq 0 \\ 0, & R E^{t} \times R E^{0}=0(4 \mathrm{c})\end{cases}$

Here, $L(a, b)=(a-b) /(\ln a-\ln b)$.

\section{DATA}

The period studied is from the year 1980 to 2012 with a five-year interval, which reflects the developing trend of urbanization and energy related variables since China's Reform and Opening up policy. The data of population $\left(10^{8}\right.$ person), urbanization (\%), the share and output of each industry $\left(\%, 10^{8}\right.$ Yuan) and per capita GDP (Yuan) are collected from China Statistic Yearbook. The constant price of the year 1978 is used in measuring GDP and outputs of different industries. With the unit of $10^{4}$ ton of standard coal equivalent, the total and sector energy consumption data are gathered from various issues of China Energy Statistic Yearbook. The energy intensity of each industry is calculated accordingly. Table 1 listed the data of urbanization (U), per capita GDP, total energy consumption (TE), energy consumption (EC) in each industry and residential energy consumption (RE).

\section{RESULTS AND DISCUSSION}

\subsection{Analysis of Energy Consumption and Urbanization}

Accompanied with rapid urbanization and economic growth, the total energy consumption in China rose from $60275 \times 10^{4}$ tce in year 1980 to $361732 \times 10^{4}$ tce in year 2012 (as shown in Fig. 2). The average annual growth rate for TE is $8.49 \%$, higher than the rate of urbanization $(4.64 \%)$, im-

Table 1. Data of urbanization, per capita GDP and energy consumption in 1980-2012.

\begin{tabular}{|c|c|c|c|c|c|c|c|}
\hline Year & U & $\begin{array}{c}\text { Per Capita } \\
\text { GDP }\end{array}$ & TE & $\begin{array}{c}\text { EC in Primary } \\
\text { Industry }\end{array}$ & $\begin{array}{c}\text { EC in Secon- } \\
\text { dary Industry }\end{array}$ & $\begin{array}{c}\text { EC in Tertiary } \\
\text { Industry }\end{array}$ & 4625 \\
\hline \hline 1980 & 19.39 & 428 & 60275 & 4692 & 39943 & 11015 \\
\hline 1985 & 23.71 & 664 & 76682 & 4045 & 52370 & 6949 & 13318 \\
\hline 1990 & 26.41 & 898 & 98703 & 4852 & 68791 & 9261 \\
\hline 1995 & 29.04 & 1512 & 131176 & 5505 & 97526 & 12400 & 15799 \\
\hline 2000 & 36.22 & 2186 & 145531 & 3914 & 105952 & 20051 & 15614 \\
\hline 2005 & 42.99 & 3374 & 235997 & 6071 & 172127 & 32493 & 25305 \\
\hline 2010 & 49.95 & 5597 & 324939 & 6477 & 237328 & 46576 & 34558 \\
\hline 2012 & 52.57 & 6522 & 361732 & 6784 & 258630 & 56651 & 39666 \\
\hline
\end{tabular}




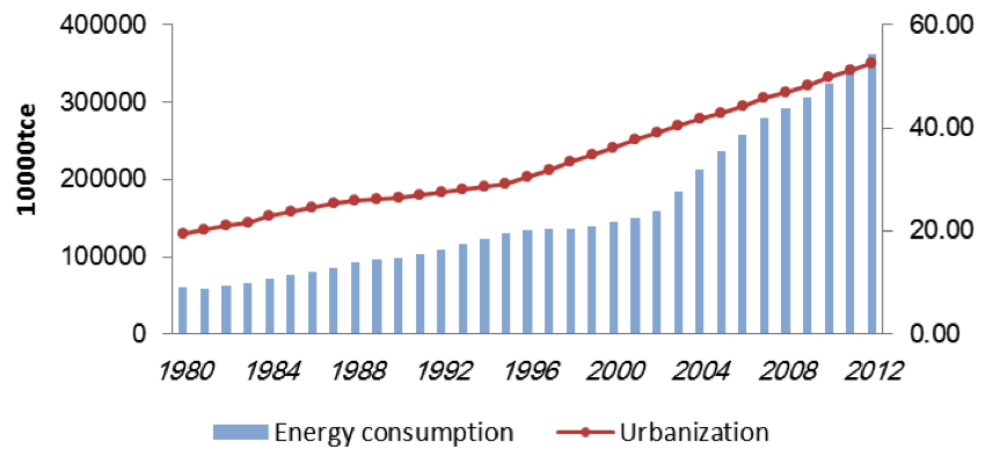

Fig (2). The trend of urbanization and energy consumption in china in 1980-2012.

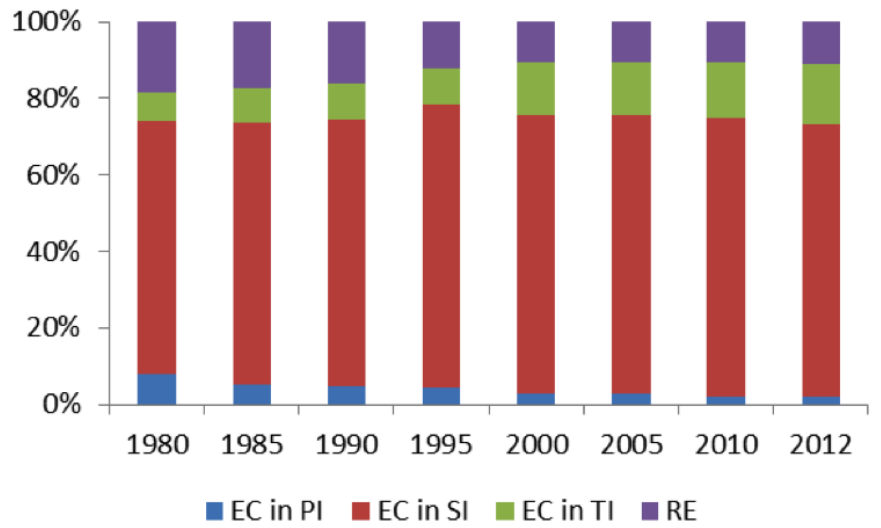

Fig (3). Share of industrial and residential energy consumption in total energy consumption.

Table 2. The decomposition result of total energy change.

\begin{tabular}{|c|c|c|c|c|c|c|c|c|}
\hline \multirow{2}{*}{ Year } & \multirow{2}{*}{$\mathbf{E}$} & \multicolumn{4}{|c|}{ PE } & \multicolumn{3}{c|}{ RE } \\
\cline { 3 - 9 } & & $\Delta \mathbf{E}_{\mathbf{P} 1}$ & $\Delta \mathbf{E}_{\text {eg }}$ & $\Delta \mathbf{E}_{\text {is }}$ & $\Delta \mathbf{E}_{\text {ti }}$ & $\Delta \mathbf{E}_{\mathbf{p} 2}$ & $\Delta \mathbf{E}_{\mathrm{ps}}$ & $\Delta \mathbf{E}_{\mathrm{ch}}$ \\
\hline \hline $1980-1985$ & 16407 & 3910.39 & 24535.66 & -4022.31 & -10319.75 & 847.85 & 1128.07 & 327.08 \\
\hline $1985-1990$ & 22021 & 5603.44 & 21929.52 & -1652.81 & -6340.15 & 1119.45 & 676.25 & 685.30 \\
\hline $1990-1995$ & 32473 & 5666.56 & 51150.11 & 9725.00 & -34014.97 & 909.41 & 576.29 & -1539.70 \\
\hline $1995-2000$ & 14355 & 5547.34 & 45080.82 & -1328.66 & -34813.25 & 710.04 & 1299.72 & -2140.85 \\
\hline $2000-2005$ & 90466 & 5207.57 & 72549.68 & 4138.47 & -1121.45 & 625.65 & 1263.01 & 7802.86 \\
\hline $2005-2010$ & 88942 & 6255.37 & 125701.83 & -1611.29 & -50655.92 & 747.79 & 1246.96 & 7257.82 \\
\hline $2010-2012$ & 36793 & 2980.81 & 46778.63 & -5707.03 & -12367.71 & 361.06 & 376.05 & 4370.98 \\
\hline
\end{tabular}

plying the energy consuming effects of urbanization overtook its energy saving effects during this period. Especially after year 2002, the curve of energy consumption increasing is obvious steeper than that of urbanization. The shares of each sector in total energy consumption also change along with urbanization (see Fig. 3). The percentage of energy consumption in primary industry (PI) decrease while the industry evolving from primary to secondary and tertiary industries (SI and TI) in the course of urbanization. As the largest energy consumer, secondary industry used nearly $70 \%$ of the total energy during the time. With the thriving of tertiary industry in urbanization, the share of energy consumption of TI increases, becoming the second largest energy consumer since 1995.

\subsection{Decomposition Analysis}

According to Equation 2, the effect of urbanization on energy consumption can be decomposed into two parts, as production sector and residential sector, including 7 effects. The decomposition result is shown as Table $\mathbf{2}$.

Comparing the effects from the two sectors in Table 2, the change of production energy is the dominating factor for the total energy consumption change compare to residential energy consumption. The change of PE and RE can be illustrated in Fig. (4).

As shown in Fig. (4), the change of production energy played a dominating part in the change of total energy con- 


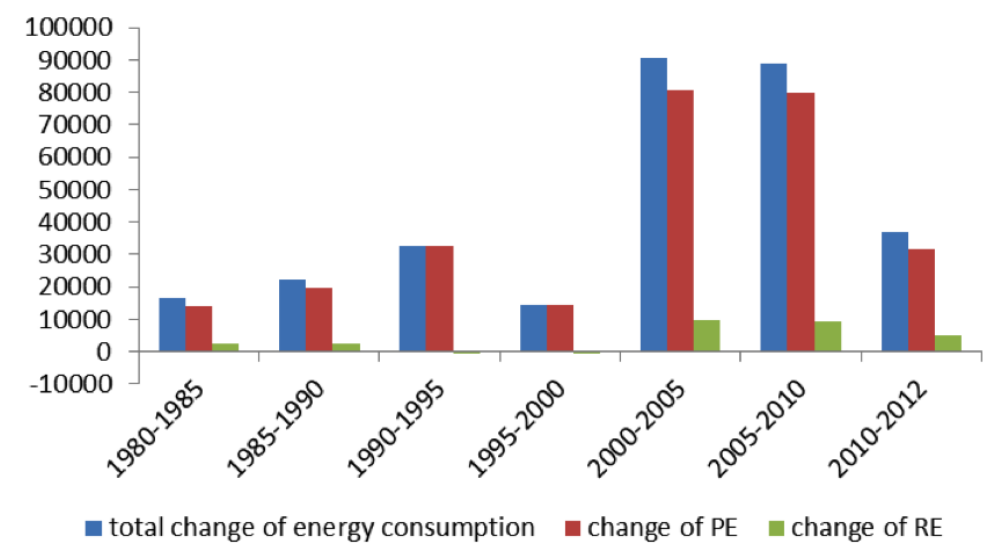

Fig (4). The share of change in PE and RE.

Table 3. The influence of each effects to the change of TE (\%).

\begin{tabular}{|c|c|c|c|c|c|c|c|}
\hline Year & $\Delta \mathbf{E}$ & $\Delta \mathbf{E}_{\mathbf{P 1}}$ & $\Delta \mathbf{E}_{\mathrm{eg}}$ & $\Delta \mathbf{E}_{\text {is }}$ & $\Delta \mathbf{E}_{\mathrm{ti}}$ & $\Delta \mathbf{E}_{\mathrm{ps}}$ & $\Delta \mathbf{E}_{\text {ch }}$ \\
\hline $1980-1985$ & 100 & 29.00 & 149.54 & -24.52 & -62.90 & 6.88 & 1.99 \\
\hline $1985-1990$ & 100 & 30.53 & 99.58 & -7.51 & -28.79 & 3.07 & 3.11 \\
\hline $1990-1995$ & 100 & 20.25 & 157.52 & 29.95 & -104.75 & 1.77 & -4.74 \\
\hline $1995-2000$ & 100 & 43.59 & 314.04 & -9.26 & -242.52 & 9.05 & -14.91 \\
\hline $2000-2005$ & 100 & 6.45 & 80.20 & 4.57 & -1.24 & 1.40 & 8.63 \\
\hline $2005-2010$ & 100 & 7.87 & 141.33 & -1.81 & -56.95 & 1.40 & 8.16 \\
\hline $2010-2012$ & 100 & 9.08 & 127.14 & -15.51 & -33.61 & 1.02 & 11.88 \\
\hline $1980-2012$ & 100 & 13.43 & 128.62 & -0.15 & -49.64 & 2.18 & 5.56 \\
\hline
\end{tabular}

sumption compare to residential energy, implying that the change of PE had more impact in total energy consumption change during urbanization. Appearing a steady increase during 1980 to 1995; a slower increase during 1995 to 2000 and a prompt increase after the year 2000, the overall tendency of the change in PE and TE are quite similar, the change is always positive in the studied period. The change of RE showed a negative sign during 1990 to 2000, implying a decrease of energy consumption in residential sector during that period.

Combine the population effect in both production and residential sector, the total population effect to energy consumption effect is conducted according to Equation X. Then the influence of the 6 effects causing the total energy consumption change can be illustrated as Table 3 .

Among the impacting factors, per capita GDP, representing the economic growth is the largest factor to drive the increase of energy consumption. While energy intensity which reflects technology improvement is the main drive for energy saving. The increase of population scale and percentage live in urban area cast positive influence on energy consumption. The impact of industrial structure and per capita household energy consumption on the total change differs in different periods.

For the entire period of 1980 to 2012, the expanding population scale counts for $13.43 \%$ of the total energy in- crease. For economic growth effect, the largest drive for the increase of energy consumption, the accumulated impact on the change of TE is $128.62 \%$. The effect of industrial structure to $\mathrm{TE}$ is $-0.15 \%$, implying the evolving of industrial structure during urbanization slightly decrease the total energy consumption. As the main drive of energy saving, the technical improvement effect contributes $-49.64 \%$ in TE change. Accounting for $2.18 \%$ and $5.56 \%$ separately, the population structure and consumption habit directly resulting from urbanization are casting positive effect on the increase of TE during 1980 to 2012.

\subsection{Production Energy Consumption Analysis}

The result of decomposition of change in energy consumption in production sector is shown in Fig. (5). Economic growth is the largest impacting factor of energy consumption increase in production sector. Highly positive correlated with urbanization, economic growth is both the cause and result of urbanization. Becoming the new engine for economic growth, urbanization boosts the construction of infrastructure, public service facilities and buildings with the expansion of cities and towns. With an annual growth rate of $8.88 \%$, economic development is always the main drive for the increasing of energy consumption from 1980 to 2012. The result indicated that the economy of China is energy dependent during urbanization. 


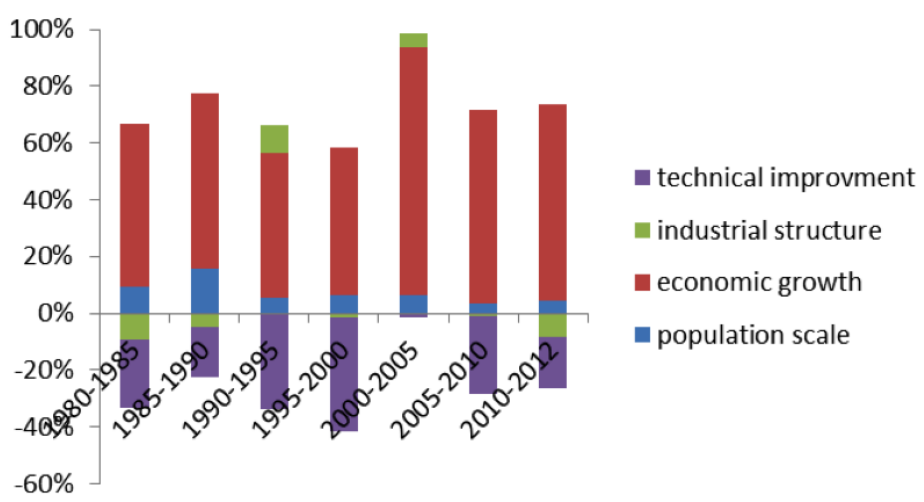

Fig (5). Decomposition of change in energy consumption in production sector.

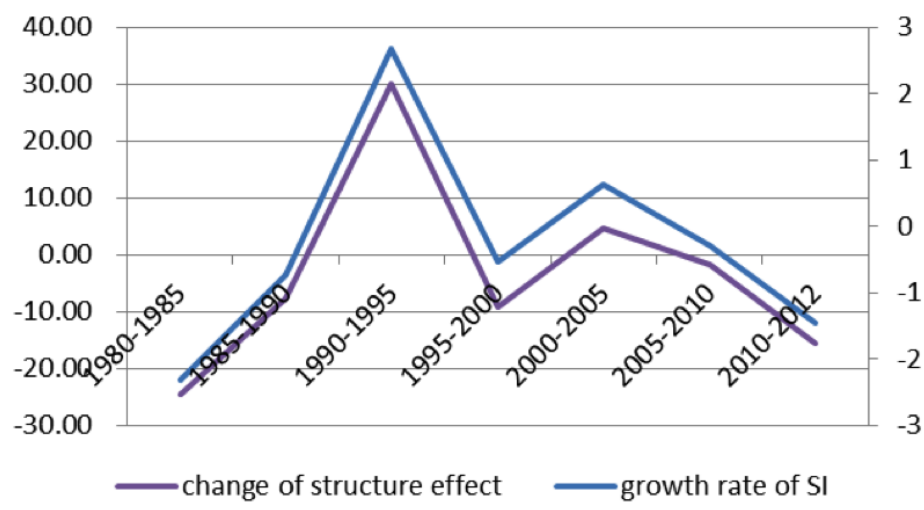

Fig (6). Change of structure effect and growth rate of secondary industry.

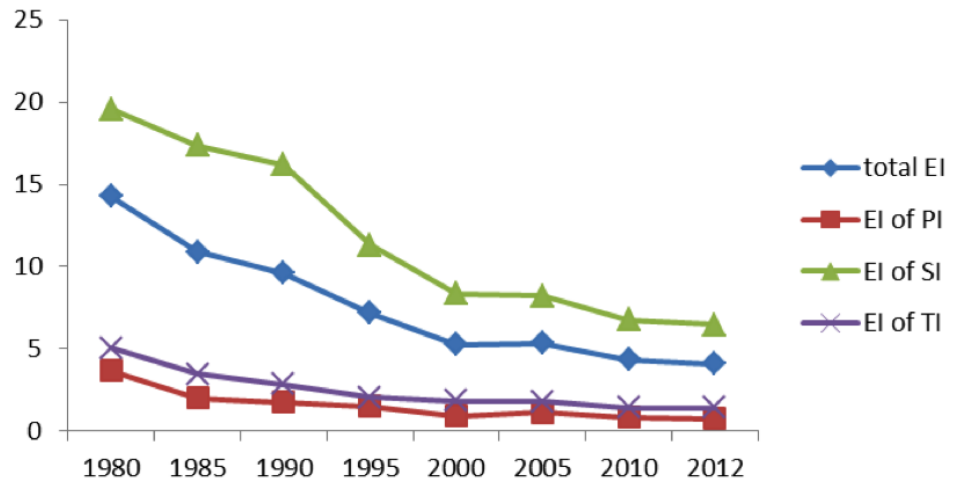

Fig (7). Change of energy intensity from 1980 to 2012.

As the urbanization further on, the share of the primary industry has shrink from $30.2 \%$ in year 1980 to $10.1 \%$ in year 2012. In the meanwhile, the secondary and tertiary industry has grown rapidly. As the largest energy consumer, the secondary industry has the largest influence in industrial energy consumption. The economic structure effect is highly complied with the change of annual growth rate (see Fig. 6). Before 1990, the effect of industrial structure decrease the energy consumption as the share of secondary industry increased slowly while the industry evolving from primary industry to more efficient secondary and tertiary industries. In the period of 1990 to 1995 , the secondary industry grew dramatically along with the rapid increase of heavy industry consuming huge amount of energy, turning the industrial structure change a driving force of energy increase. With the impact of the Asian financial crises in 1998, the exportoriented manufacturing industries shrunk during 1995 to 2000. The drop in the secondary industry brought a slight decrease in total energy consumption. With the recovery of macro economy during 2000 to 2005, secondary industry rebounded and pushed the consumption of energy. After the year of 2005, the share of secondary industry decreased as economy shifting into tertiary industry. The evolving of industrial structure helped in energy saving after 2005.

Reflecting the technical improvement level, the energy intensity of the overall economy and separate industries are decreasing during the study period except a slight increase in 2000-2005 (see Fig. 7). The total energy intensity decreased from 14.25 in 1980 to 4.10 in 2012 with help of technical transfer and spillover during urbanization. 


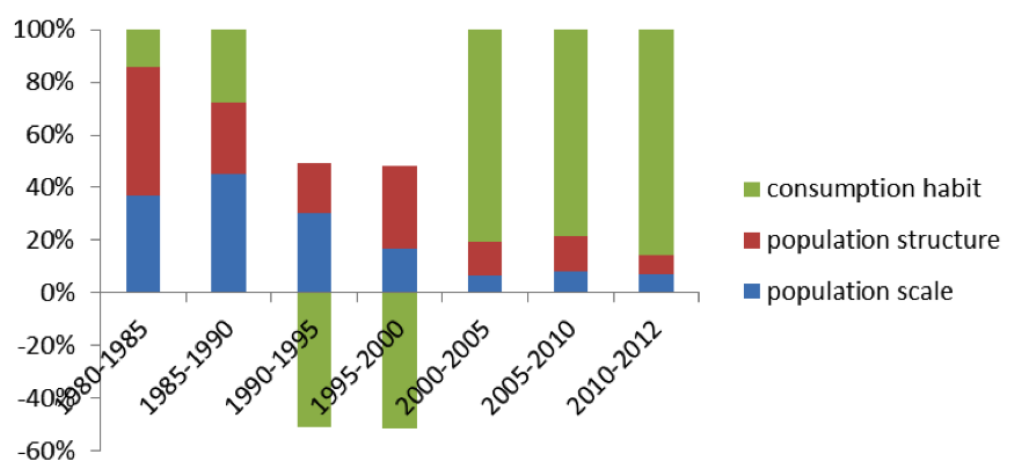

Fig (8). Decomposition of change in energy consumption in residential sector.

Table 4. Comparison of urban and rural direct RE.

\begin{tabular}{|c|c|c|c|c|c|}
\hline Year & $\begin{array}{c}\text { Urban Direct } \\
\operatorname{RE}\left(10^{4} \text { tce }\right)\end{array}$ & $\begin{array}{l}\text { Urban Per Capita } \\
\text { Direct RE (kgce) }\end{array}$ & $\begin{array}{c}\text { Urban Direct RE } \\
\left(10^{4} \text { tce }\right)\end{array}$ & $\begin{array}{l}\text { Urban Per Capita } \\
\text { direct RE (kgce) }\end{array}$ & $\begin{array}{c}\text { Ratio of U/R Per } \\
\text { Capita RE }\end{array}$ \\
\hline 1991 & 8050.87 & 292 & 6428.27 & 83 & 3.51 \\
\hline 1995 & 6743.92 & 242 & 6162.19 & 86 & 2.83 \\
\hline 2000 & 6500.76 & 210 & 4185.19 & 76 & 2.74 \\
\hline 2005 & 9642.53 & 279 & 6689.53 & 132 & 2.11 \\
\hline 2010 & 14827.22 & 315 & 9646.96 & 204 & 1.55 \\
\hline 2012 & 17021.03 & 339 & 10799.13 & 246 & 1.38 \\
\hline
\end{tabular}

*Data gathered from China Energy Statistic Yearbook

Table 5. Amount of urban and rural household energy consuming appliance in 2012.

\begin{tabular}{|c|c|c|c|c|c|}
\hline & Rural & Urban & & Rural & Urban \\
\hline \hline Washing Machine & 98.02 & 67.22 & Color TV & 136.07 & 116.9 \\
\hline Refrigerator & 98.48 & 67.32 & Camera & 46.42 & 5.18 \\
\hline Air conditioner & 126.81 & 25.36 & Computer & 87.03 & 21.36 \\
\hline Mobile phone & 212.64 & 197.8 & Car & 21.54 & 6.59 \\
\hline
\end{tabular}

*Data gathered from China Statistic Yearbook

\subsection{Residential Energy Consumption}

The result of decomposition of change in energy consumption in residential sector is shown in Fig. (8). In residential sector, the population structure has the largest influence on energy consumption before 1985. The population structure has a positive impact on residential energy consumption, which implies residents tend to use more energy when they move into urban area.

The impact of consumption habit represented by per capita energy consumption increasing during the period and became the main impacting factor since 1990; the fluctuation of energy consumption in residential sector follows its change. In the time interval of 1990 to 2000 , the residential energy consumption decreased. The possible reason is the obvious inflation during that period causing decrease of household real income and urged residents saving the household energy consumption.
The residential energy consumption can be divided into direct residential energy consumption (referring the energy directly consumed in daily life activities, such as cooking, lighting, air conditioning and so on) and indirect residential energy consumption (referring the energy consumption embodied in the products and services consumed), both of which are closely related to the population structure and consumption habit. Consuming more fuels and electricity in daily life, urban residents also possess more products (such as household appliance) and services which leading more direct and indirect energy consumption (see Tables $\mathbf{4}$ and $\mathbf{5}$ ). Listing the total and per capita direct residential energy consumption data from 1991 to 2012, Table 4 showed their difference in the urban and rural area. Both urban and rural direct residential energy consumption increased during urbanization. The gap has been narrowed from 3.51:1 to 1.38:1 but the difference is still obvious. Taking the main household energy consuming appliance as an example, the differences in energy consumption can also be detected. 


\section{CONCLUSION AND SUGGESTIONS}

Applying LMDI method, the effects of urbanization to energy consumption was divided into production sector and residential sector. Playing a leading role in the change of total energy consumption, the change of production energy consumption caused by urbanization is decomposed into population scale effect, economic growth effect, industrial structure effect and technical improvement effect. Among which, economic growth is the main driving force of the increasing of energy consumption while technical improvement exerting the opposite influence. The dominating factor of energy consumption variation in residential sector shifted from population structure to consumption habit.

Based on the results and analysis above, suggestions in reducing energy consumption in the process of urbanization are given as follows:

(1) Focusing on the quality of the economic growth and urbanization development while keep the growth rate at a proper level. In current status, the economic growth is the largest drive for the increase of total energy consumption. To reduce the dependency of growth on energy consumption, the agglomeration effect of urbanization should be fully used of. Replace fossil fuels by cleaner and renewable energies.

(2) Advance the development of technology to lower the energy intensity and improve energy efficiency. The progress in technical improvement helps saving energy in the process of the exploitation, production as well as its consumption. However, producers and households tend to use more energy when the energy efficiency improves as it brought down energy price and raised their real income. The rebound effect should be paid attention to.

(3) Optimizing industrial structure by developing service industry. As the foundation of urban economy, the industry growth plays a crucial role in the development of urbanization. Growing in a low-efficient, heavy-polluted, easyreplaced and poor-performed way, the heavy industries such as steel industry, chemical industry and cement industry are posing challenges for the further prosperous of Chinese urban area. To maintain a sustainable urban growth, the industries with low energy emission, low pollution and low emission should given priority to. The servitization of the secondary industry should further on while the development of tertiary industry speeds up.

(4) Constructing an energy conservative economy. Being the third largest energy consuming sector in China, residential energy use is growing rapidly with a growing proportion in total energy consumption. Advocating energy conservative notion to the entire society is a wise decision to make. Avoiding the residential energy use from excessive growth does not mean preventing residents to enjoy the advanced way of life or improved living standard, but providing high quality public service and forbidding unnecessary waste at the same time. Take Green Transportation as an example, build a more convenient, integrated public transportation network is a better way than ban private cars.

\section{CONFLICT OF INTEREST}

The authors confirm that this article content has no conflict of interest.

\section{ACKNOWLEDGEMENTS}

The authors gratefully acknowledge the financial support from the Jiangsu Provincial Graduate Innovation Project (KYZZ_0382), the Fundamental Research Funds for the Natural Science Foundation of Jiangsu Province (BK20130176) and the Fundamental Research Funds for the Central Universities (2013XK01).

\section{REFERENCES}

[1] D. W. Jones, "How urbanization affects energy use in developing countries," Energy Policy, vol. 19, no. 7, pp. 621-30, 1991.

[2] J. Parikh, and V. Shukla, "Urbanization, energy use, and greenhouse effects in economic development: results from a crossnational study of developing countries," Global Environmental Change, vol. 5, no. 2, pp. 87-103, 1995.

[3] H. Imai, "The effect of urbanization on energy consumption," Journal of Population Problem, vol. 53, no. 2, pp. 43-9, 1997.

[4] J. R. Kenworthy, and F. B. Laube, "Auto mobile dependence in cities: an international comparison of urban transport and land use patterns with implications for sustainability," Environmental Impact Assessment Review, vol. 16, no. 4, pp. 279-308, 1996.

[5] R. Ewing, and F. Rong, "The impact of urban form on U.S. residential energy use," Housing Policy Debate, vol. 19, no. 1, pp. 130, 2008.

[6] V. Mishra, R. Smyth, and S. Sharma, "The energy-GDP nexus: evidence from a panel of pacific island countries," Resource and Energy Economics, vol. 31, no. 3, pp. 210-220, 2009.

[7] M. Shahbaz, and H. H. Lean, "Does financial development increase energy consumption? The Role of Industrialization and Urbanization in Tunisia," Energy Policy, vol. 40, pp. 473-479, 2012.

[8] B. R. Wei, H. Yagita, A. Inaba, and M. Sagisaka, "Urbanization impact on energy demand and $\mathrm{CO}_{2}$ emission in China," Journal of Chongqing University-Eng, vol. 5, no. 2, pp. 46-50, 2003.

[9] Y. Liu, "Exploring the relationship between urbanization and energy consumption in China using ARDL and FDM," Energy vol. 34, no. 11, pp. 1846-1854, 2009.

[10] S. Lin, D. Zhao, and D. Marinova, "Analysis of the environmental impact of China based on STIRPAT model," Environmental Impact Assessment Review, vol. 29, pp. 341-347, 2009.

[11] R. Madlener, and Y. Sunak, "Impacts of urbanization on urban structures and energy demand: What can we learn for urban energy planning and urbanization management?," Sustainable Cities and Society, vol. 1, pp. 45-53, 2011.

[12] I. Martínez-Zarzoso, and A. Maruotti, "The impact of urbanization on CO2 emissions: Evidence from developing countries," Ecological Economics, vol. 70, pp. 1344-1353, 2011.

[13] Q. Wang, "Effects of urbanisation on energy consumption in China," Energy Policy, vol. 65, pp. 332-339, 2014.

[14] C. Ma, and D. Stern, "China's changing energy intensity trend: a decomposition analysis," Energy Economics, vol. 30, pp. 1037$1053,2008$.

[15] D. Guan, K. Hubacek, C.L. Weber, G.P. Peters, and D.M. Reiner, "The drivers of Chinese $\mathrm{CO}_{2}$ emissions from 1980 to 2030," Global Environmental Change, vol. 18, pp. 626-634. 2008.

[16] S. Lindner, J. Legault, and D. Guan, "Disaggregating the electricity sector of China's input-output table for improved environmental life-cycle assessement," Economic Systems Research, vol. 25, pp. 300-320, 2013.

[17] M. Zhang, and F. Guo, "Analysis of rural residential commercial energy consumption in China,” Energy, vol. 52, pp. 222-229, 2013.

[18] K.S. Feng, Y.L. Siu, D.B. Guan, and K. Hubacek, "Analyzing drivers of regional carbon dioxide emissions for china a structural decomposition analysis," Journal of Industrial Ecology, vol. 16, pp. 600-611, 2012.

[19] Z. Liu, Y. Geng, S. Lindner, and D. Guan, "Uncovering China's greenhouse gas emission from regional and sectoral perspectives," Energy, vol. 45, pp. 1059-1068, 2012.

[20] W.W. Wang, M. Zhang, and M. Zhou, "Using LMDI method to analyze transport sector $\mathrm{CO}_{2}$ emissions in China," Energy, vol. 36, pp. 5909-5915, 2011. 
[21] B. Ang, "Decomposition analysis for policy making in energy: which is the preferred method?," Energy Policy, vol. 32, pp. 1131$1139,2004$.
[22] B. Ang, and N. Liu, "Energy decomposition analysis: IEA model versus other methods," Energy Policy, vol. 35, pp. 1426-1432, 2007.

Received: June 10,2015

Revised: July 29, 2015

Accepted: August 15, 2015

(C) Guan and Zhou; Licensee Bentham Open.

This is an open access article licensed under the terms of the (https://creativecommons.org/licenses/by/4.0/legalcode), which permits unrestricted, noncommercial use, distribution and reproduction in any medium, provided the work is properly cited. 